\title{
METAS DE SOCIALIZAÇÃO DE PAIS E MÃES PARA SEUS FILHOS
}

\section{MOTHERS'AND FATHER'S SOCIALIZATION GOALS FOR THEIRS CHILDREN}

\author{
Tatiana T. A. Bandeira ${ }^{1}$ \\ Maria Lucia Seidl de Moura ${ }^{2}$ \\ Mauro Luís Vieira ${ }^{3}$
}

Bandeira TTA; Moura MLS; Vieira ML. Metas de socialização de pais e mães para seus filhos. Rev Bras Crescimento Desenvolv Hum. 2009; 19(3): 445-456.

\section{Resumo:}

as expectativas que pais têm em relação aos filhos fazem parte do contexto sociocultural onde esses se desenvolvem. Geralmente, estudos sobre o tema focalizam apenas crenças maternas. Este trabalho objetivou investigar metas de socialização que pais e mães apresentam em relação ao futuro de seus filhos e o que pensam sobre como alcançá-las. Participaram do estudo trinta casais do Rio de Janeiro, com filho único até três anos. Eles responderam a uma forma adaptada do questionário desenvolvido por R. Harwood e seus colaboradores. As respostas foram analisadas segundo cinco categorias, especificadas na literatura, que indicam tendências de socialização para autonomia, interdependência ou autonomia-relacional. Os resultados mostraram que pais e mães valorizam metas relacionadas à autonomia e também à interdependência. Além disso, acreditam que a melhor forma para alcançar essas metas seriam o ensinamento e o bom exemplo dos pais. Em geral, pais e mães apresentaram respostas semelhantes. Este estudo traz uma contribuição à literatura da área, especialmente em relação a crenças paternas e sua comparação com idéias das mães sobre socialização de seus filhos.

Palavras-chave: metas de socialização; maternidade; paternidade.

1 Departamento de Psicologia. Universidade do Estado do Rio de Janeiro - Rua Curupaiti 347 apt 105 Méier - Cep: 20735-320. Rio de Janeiro-RJ. tatitargino.targino@gmail.com

2 Departamento de Psicologia. Universidade do Estado do Rio de Janeiro. mlseidl@gmail.com

3 Mauro Luís Vieira. Departamento de Psicologia. Universidade Federal de Santa Catarina. maurolvieira@gmail.com Correspondência para: Tatiana T. A. Bandeira. E-mail: tatitargino.targino@gmail.com 


\begin{abstract}
:
parents' expectations regarding their children are part of the socio-cultural context where they grow. In general, studies about this subject focus only mothers' beliefs. This work aims to investigate mothers' and fathers' socialization goals regarding the future of their children, and their beliefs about how to reach those goals. The participants are thirty married couples from Rio de Janeiro with children aged one to three. They have answered open questions adapted from the Socialization Goals Interview developed by R. Harwood and collaborators. The answers were analyzed according to five categories specified in the literature, which represent tendencies of socialization for autonomy, interdependence and relational autonomy. The results indicate that parents value both goals related to autonomy and to interdependence. Besides, they believe that the best way to reach those goals should be through education and the good example of the parents. In general, fathers and mothers have given similar answers. The study brings a contribution to the literature of the area, especially in regard to fathers' beliefs and the comparison with mothers' ideas about socialization of their children.
\end{abstract}

Key words: socialization goals; motherhood; fatherhood.

\section{INTRODUÇÃO}

Estudos sobre cognições parentais (entendidas aqui como sistemas de crenças e valores, expectativas ou metas de socialização que os pais e mães possuem sobre como são e/ ou como serão seus filhos) são importantes na medida em que possibilitam compreender sobre a qualidade do cuidado e possíveis influências no desenvolvimento infantil ${ }^{1,2}$. Além disso, também permitem abrir novos caminhos para se pesquisar a cultura e o desenvolvimento humano. ${ }^{3}$

Um dos termos utilizados para se referir aos sistemas de crenças e valores de mães e pais sobre crianças de modo geral e filhos, de modo específico, é etnoteorias parentais, que são definidas como construções pessoais, coletivamente organizadas por indivíduos que assumem papéis parentais e por crenças culturais e ideologias comunicadas na forma de sugestões sociais ${ }^{4}$. Esses sistemas de crenças parentais fazem parte do modelo de nicho de desenvolvimento proposto por Harkness e Super. ${ }^{3}$ Para esses autores, o nicho de desenvol- vimento, contexto em que se dá o desenvolvimento infantil, pode ser concebido como um sistema organizado em três subsistemas que se influenciam mutuamente: ambiente físico e social, costumes de cuidado e as etnoteorias parentais. Estas envolveriam as crenças e expectativas dos pais em relação a sua criança, englobando as metas de socialização, consideradas aqui como valores. Os valores que os pais desejam para os filhos exercem uma função fundamental no desempenho do papel parental, estabelecendo objetivos ou metas e influenciando na escolha da melhor estratégia de criação dos seus filhos. ${ }^{5}$

Segundo Biasoli-Alves ${ }^{6}$, valores, práticas e papéis desempenhados na sociedade estão em constante mudança. Especificamente entre o final do século XIX e início do Xx, para essa mesma autora, os valores mais enfatizados tanto para meninos, como para meninas eram: respeito, obediência, honestidade e trabalho. Para as meninas, almejava-se também a submissão, delicadeza no trato, pureza, capacidade de doação, prendas domésticas e habilidades manuais e o estudo não era incentivado. 
Nas décadas de 1930 a 1950, a entrada de meninas na escola fica mais viável, mas continuam as diferenças entre as expectativas em relação à vida escolar e profissional de homens e mulheres. Na segunda metade do século xx, observa-se gradualmente uma maior valorização da inteligência e da competência da mulher, no entanto a grande importância dada ao casamento e suas funções como esposa ainda permanecem. Nas últimas décadas do século xx evidenciam-se uma maior escolarização e profissionalização da mulher, mas elas são ainda percebidas como as principais responsáveis pela casa, marido e filhos.

Além dessas tendências, constata-se desde meados da década de 1970 uma grande incerteza e insegurança dos pais em relação à melhor forma de criar os filhos. A preocupação maior não é tanto que eles sejam bem educados e respeitem os mais velhos para causar boa impressão, mas a grande aflição diz respeito ao futuro e às possíveis conseqüências negativas de algumas práticas de cuidado e educação. ${ }^{6}$

Através do estudo das metas de socialização dos pais podemos conhecer alguns aspectos do modelo cultural da população estudada. Para Keller, Borke e Yovsi ${ }^{7}$, os modelos culturais podem ser orientados para o desenvolvimento da autonomia ou da interdependência. $\mathrm{O}$ primeiro se caracteriza pela construção de um self único e distinto, em que se priorizam as metas pessoais e a autonomia. O último concebe a construção do self conectado a outras pessoas, enfatizando os deveres e obrigações em um grupo social. Além dessas duas orientações, Kagitçibasi ${ }^{8,9}$ propôs uma terceira orientação, que denomina de autônomo-relacional, envolvendo características dos outros dois modelos. Ela se refere a um self que, ao mesmo tempo em que é autônomo, mostra-se interdependente e se concebe como membro de uma família e de uma comunidade.

Considerando essas diferentes orientações, Keller, Lamm, Abels , Yovsi, Borke,
Jensen et al ${ }^{10}$ realizaram uma pesquisa envolvendo mães de diferentes localidades dos três modelos culturais. Foram elas: 36 mães alemãs, 21 americanas de origem européia e 46 gregas, todas de famílias urbanas, maior escolaridade e de classe média, representando o modelo independente; 16 agricultoras de Camarões e 12 aldeães da Índia, ambas de baixa escolaridade, retratando o modelo interdependente; e representando o modelo autônomo-relacional, foram recrutadas 21 mães costarriquenhas, 12 mexicanas, 23 indianas e 17 chinesas, de famílias urbanas, maior escolaridade e de classe média. As participantes tinham um filho de três meses de idade. Para avaliar as metas de socialização valorizados por elas, foi utilizado um questionário com 10 metas, sendo cinco relacionadas à autonomia (ex: desenvolver autoconfiança) e as outras cinco voltadas para metas relacionais (ex: obedecer a pessoas mais velhas). As mães tinham que marcar em uma escala tipo Likert que variava de não concordo nem um pouco a concordo completamente se as crianças deveriam até os três anos de vida desenvolver as metas mencionadas. Os resultados mostraram que o grupo do modelo cultural independente apresentou um baixo escore em relação a metas de socialização que valorizam a relação, ao contrário do grupo interdependente. Já as mães que representavam o modelo autônomo-relacional ocuparam uma posição intermediária. Em relação às metas de socialização valorizando a autonomia, elas tiveram um escore tão alto quanto o grupo do modelo independente. Já as mães que representavam o modelo interdependente tiveram um escore mais baixo nesse aspecto. Segundo os autores citados, esses resultados podem demonstrar que famílias urbanas e educadas estão mudando e se adaptando a diferentes estilos de vida.

O estudo de Leyendecker, Harwood, Lamb e Sholmerich ${ }^{11}$ enfatizou as metas de socialização a longo prazo e avaliação de situações diárias consideradas como desejáveis 
ou indesejáveis em mães latinas que migraram para os Estados Unidos e mães norte-americanas de origem européia. Foi utilizado um questionário de metas de socialização, e as respostas das mães foram codificadas em cinco categorias: autoaperfeiçoamento, autocontrole, emotividade, expectativa social e bom comportamento. O primeiro grupo de mães enfatizou qualidades de bom comportamento, enquanto o outro grupo valorizou mais metas de autoaperfeiçoamento e autocontrole. Além disso, verificou-se que mães da América Central davam mais importância para a qualidade de autocontrole quando a criança era do sexo masculino. Com relação às mães de origem européia de meninos, eram mais enfatizadas as qualidades referentes às expectativas sociais (decência, honestidade) e as mães de meninas valorizavam o autoaperfeiçoamento, principalmente relacionado ao bem estar emocional e físico.

Especificamente no caso do Brasil, nos últimos anos tem sido publicado pesquisas sobre o que as mães esperam dos seus filhos no futuro. Um deles foi realizado por Moinhos et al $^{1}$ na cidade de Salvador com 50 mães. Através da análise dos resultados, as autoras chegam a conclusão de que existem metas similares entre mães de diferentes níveis socioeconômicos. De modo geral, as metas que foram mencionadas com maior freqüência pelas mães foram expectativas sociais, autoaperfeiçoamento e bom comportamento, indicando haver na amostra pesquisada um ambiente cultural em que as mães possuem, de certo modo, valores e crenças compartilhadas com relação ao que elas desejam para seus filhos.

Em outro estudo que envolveu a participação de 350 mães em sete capitais do Brasil, distribuídas nas cinco regiões geográficas do país, sendo 50 de cada local, Seidl-de-Moura, Lordelo, Vieira, Piccinnini, Siqueira, Magalhães et al $^{12}$ analisaram diferenças e semelhanças de metas de socialização. Para a coleta dos dados foi utilizado o questionário adaptado de metas de socialização desenvolvido por Harwood e colaboradores ${ }^{13}$, que objetivava saber as qualidades que as mães gostariam que seus filhos tivessem como adultos. Os resultados mostraram que, em geral, as mães brasileiras valorizaram mais metas de autoaperfeiçoamento, que é voltada para autonomia e independência e também as metas de expectativa social, a qual está relacionada à interdependência e o pertencimento grupal. Esse dado, de alguma forma, também se assemelha ao que aconteceu na amostra do estudo de Moinhos et al ${ }^{1}$, anteriormente citado. Com isso, é possível perceber que as mães, tanto na amostra de Salvador, como na amostra mais abrangente em termos de Brasil, parecem apresentar um modelo cultural autônomorelacional.

Por outro lado, a maioria dos estudos relatados não inclui os pais, que reconhecidamente têm papel importante na criação dos filhos e em seu desenvolvimento. Participando da vida dos filhos, os pais oferecem a eles um senso de segurança e apoio emocional, entre outros aspectos. ${ }^{14}$ Para investigar as expectativas dos pais em relação aos seus filhos, Prado ${ }^{15}$ efetuou uma pesquisa com pais e mães de Florianópolis e analisou quais metas de socialização eram mais valorizadas por eles e o que acreditavam que deveria ser feito para alcançarem essas metas. Participaram do estudo 27 pais e 29 mães com pelo menos um filho na faixa etária de três a seis anos. Os resultados indicaram que as metas mais valorizadas por pais e mães foram de autoaperfeiçoamento e expectativas sociais, e a que foi menos relatada foi a de autocontrole. Os pais valorizaram um pouco mais o autoaperfeiçoamento, ou seja, tiveram a preocupação com que a criança se tornasse autoconfiante e independente e as mães deram mais importância para que o seu filho atendesse às expectativas sociais. No entanto, estatisticamente não foi constatada diferença significativa entre pais e mães para ne- 
nhuma das metas. Ou seja, eles pensam de forma semelhante em relação a esse tema. Quanto ao nível de escolaridade, foi identificada uma tendência na pesquisa de Prado ${ }^{15}$ dos participantes com nível de escolaridade superior apresentarem maior escore para autoaperfeiçoamento quando comparados a pessoas de nível de ensino fundamental. Além disso, tanto pais quanto mães mencionaram mais respostas voltadas para interdependência. Em relação às estratégias de ação para atingir as tais metas, ambos acreditam que é uma função deles, que eles devem dar conselhos, bons exemplos, etc.

Reconhecendo a relevância do estudo sobre metas de socialização e admitindo a importância de se conhecer também a opinião dos pais sobre esse tema, o presente trabalho tem como objetivo investigar quais são as metas e expectativas que pais e mães têm em relação ao futuro de seu filho e o que pensam sobre a forma como estas podem ser atingidas.

\section{MÉTODO}

\section{Participantes}

Participaram dessa pesquisa 30 casais que tinham apenas um filho e viviam juntos no Estado do Rio de Janeiro, Brasil, na região metropolitana da cidade do Rio de Janeiro, capital do Estado. O Rio de Janeiro é um dos estados da região sudeste, a mais rica do país, em termos econômicos. A cidade do Rio de Janeiro foi a capital do país por dois séculos até os anos de 1960 e recebe migrantes de vários estados, em especial do nordeste. É a segunda maior cidade do país (com uma população de 6.094.183 habitantes, um IDH de 0.842, e PNB per capita de 5.114).

\section{Instrumentos}

Ficha de dados sociodemográficos: contém informações sobre a família tais como idade, escolaridade, profissão e estado civil dos participantes, além da idade e sexo da criança.
Questionário sobre metas de socialização - Desenvolvido por Harwood e colaboradores ${ }^{13}$ inclui quatro perguntas, mas, no presente estudo foram feitas apenas as duas primeiras já que foi percebido em estudos anteriores ${ }^{13}$ que elas eram mais informativas. São elas:

1. Que qualidades você desejaria que seu filho(a) tivesse como adulto?

2. O que você acha que é necessário para que ele(a) possa desenvolver essas qualidades?

Folha de relatório - Contém dados dos participantes como nome, endereço, telefone, além de conter algumas observações e possíveis intercorrências que possam ter acontecido no momento da realização da pesquisa.

Termo de consentimento livre e esclarecido - Documento que pais e mães assinaram aceitando oficialmente participar da pesquisa.

Procedimentos de coleta, redução e análise de dados

O projeto foi submetido ao Comitê de Ética da UERJ tendo o protocolo de número 003.3.2006 e aprovado. Os pais foram entrevistados individualmente e separadamente em local e data de sua conveniência pelo primeiro autor e assinaram o Termo de Consentimento. Suas respostas foram gravadas em áudio com sua concordância. As respostas dos pais ao questionário sobre metas de socialização, após a transcrição, foram submetidas a análise de conteúdo segundo categorias previamente definidas. A primeira pergunta envolveu as seguintes categorias, que foram utilizadas nos estudos de Harwood e colaboradores ${ }^{13}$ :

Autoaperfeiçoamento (AA) - preocupação com que a criança se torne autoconfiante e independente, e que desenvolva totalmente seus talentos e capacidades como indivíduo; Autocontrole (AC) - preocupação com que a criança desenvolva a capacidade de controlar impulsos negativos de ganância, agressão ou egocentrismo; Emotividade (EM) - preocupação com que a criança desenvolva a capacida- 
de para intimidade emocional com outros, e que seja amada; Expectativas sociais (ES) preocupação com que a criança atenda a expectativas sociais de ser trabalhador, honesto e seguidor das leis; Bom comportamento (BC) - preocupação com que a criança se comporte bem, se dê bem com os outros, e desempenhe bem papéis esperados (bom pai, boa mãe, boa esposa, etc), especialmente em relação à família.

As respostas da primeira pergunta foram classificadas também nas dimensões individualista e sociocêntrica: Individualista - construção do self como fundamentalmente único e distinto; independência, autonomia, autoestima, felicidade, autocontrole para se tornar uma pessoa melhor; autoaperfeiçoamento; autossuperação; Sociocêntrica - construção do self como fundamentalmente ligado a outros seres. Envolve interdependência social, ênfase no respeito, rede social, pertencimento a grupo ou coletividade.

São consideradas respostas individualistas aquelas que se enquadram nas categorias de autoaperfeiçoamento e autocontrole e sociocêntricas aquelas que são codificadas nas categorias de emotividade, expectativas sociais e bom comportamento.

As respostas da segunda pergunta foram classificadas em termos de possíveis estratégias de ação: Centradas em si (CS) - os pais seriam modelos ou ofereceriam modelos, iriam disciplinar, aconselhar, ensinar por demonstração ou participação. Esta categoria pode ser dividida em duas classificações que envolvem dois aspectos - Cognitivo (CSC) - O papel dos pais seria educar, orientar, ensinar, etc. - Afetivo (CSA) - O papel dos pais seria dar amor, atenção, carinho, etc.; Centradas no contexto (CC) - oferecer boas oportunidades sociais; dar educação de qualidade, etc.; Centradas na criança (CCr) - quando a criança tem participação ativa no processo de desenvolver determinadas qualidades por uma predisposição ou por uma autonomia de decidir o que fazer e que caminho seguir.
Para garantir a fidedignidade, as respostas eram analisadas por duas duplas separadamente e depois as análises eram confrontadas para garantir a concordância na categorização. Na primeira pergunta, a partir do número total de respostas dada por cada participante, a percentagem de respostas para cada categoria foi calculada. Os dados obtidos nessas categorias por mães e pais são apresentados também por estatística descritiva (média e desvio padrão). A comparação entre as variáveis foi feita através do teste de correlação de Pearson e pelo teste $t$ de Student, considerando-se estatisticamente significativas as diferenças com $\mathrm{p}<\mathrm{ou}$ igual 0,05 . Em relação à segunda pergunta foi feita uma análise qualitativa assinalando o aparecimento ou não das estratégias de ação e a porcentagem de cada uma delas em relação aos participantes. Finalmente, em relação aos dados sociodemográficos, idade e escolaridade do casal e o sexo do bebê foram relacionadas com outras variáveis.

\section{RESULTADOS E DISCUSSÃO}

\section{Características sociodemográficas dos participantes}

Dentre os participantes, vinte e dois casais eram casados oficialmente. A idade das mães variou de 20 a 40 anos tendo uma média de aproximadamente 30 anos $(M=30,3)$. Elas tinham o nível de escolaridade variando de fundamental incompleto a pós-graduação, sendo que $70 \%$ tinha pelo menos concluído a graduação. Os pais tinham entre 19 e 50 anos, com uma média de aproximadamente 34 anos $(\mathrm{M}=$ 34,33). O nível de escolaridade dos homens teve a mesma variação das mulheres: de fundamental incompleto a pós-graduação e $66,6 \%$ tinha curso superior. Seus filhos tinham idades entre zero e três anos, sendo quinze deles do sexo feminino.

Primeira pergunta: Metas de socialização 
relatadas pelos participantes

Com relação à pergunta 1 "Que qualidades eles desejariam que o seu filho tivesse quando adulto”, foram encontradas 202 respostas para as mães e 184 para os pais, tendo uma média de 6,7 respostas para as mulheres e 6,1 para os homens. Na tabela 1 encontram-se as porcentagens de distribuição das categorias das metas de socialização em função das respostas dos respondentes, demonstrando que pais e mães deram mais respostas de autoaperfeiçoamento e expectativas sociais e menos de autocontrole.

Tabela 1: Percentual de respostas de pais e mães nas categorias de metas de socialização

\begin{tabular}{lrc}
\hline Categorias & Mães & Pais \\
\hline Auto-aperfeiçoamento & $40 \%$ & $41 \%$ \\
Autocontrole & $5 \%$ & $2 \%$ \\
Emotividade & $12 \%$ & $8 \%$ \\
Expectativas sociais & $31 \%$ & $30 \%$ \\
Bom comportamento & $12 \%$ & $19 \%$ \\
\hline
\end{tabular}

Foi possível perceber que pais e mães valorizaram as cinco categorias na mesma ordem. A categoria de autoaperfeiçoamento teve um percentual maior, acompanhada de expectativas sociais que também foi considerada bastante importante, seguida de bom comportamento, emotividade e autocontrole. Prado ${ }^{15}$ encontrou resultado semelhante em seu estudo em Florianópolis, com a diferença que, em seu trabalho, a categoria autoaperfeiçoamento apresentou um percentual maior entre os pais (33\%) e entre as mães foi a categoria expectativas sociais $(35,9 \%)$.

A ênfase na categoria autoaperfeiçoamento pode apoiar o que foi explanado por Biasoli-Alves. ${ }^{6}$ Segundo a autora, a partir da metade da década de 1970 os pais começaram a ficar mais preocupados com o futuro, com o "vir a ser" de seus filhos e essa categoria envolve características que promoveriam um futuro melhor, como, por exemplo: ter dinheiro, uma boa profissão, saber cuidar de si, ter objetivos na vida, entre outras que se referem ao desenvolvimento pessoal em vários planos.

A comparação entre as médias das respostas dos pais e das mães em todas as categorias através do teste- $t$ de Student, considerando estatisticamente significativa às diferenças com $\mathrm{p}<$ ou igual 0,05 não evidenciou diferenças significativas. Além disso, foram feitas correlações de Pearson entre todas as categorias de metas de socialização e as variáveis sociodemográficas, tais como, idade e escolaridade. A tabela 2 mostra as correlações significativas verificadas nas mães ao nível de $\mathrm{p}<$ ou igual a 0,05 .

Tabela 2: Correlações significativas entre as categorias de metas de socialização das mães

\begin{tabular}{cc}
\hline Categorias & Correlação \\
\hline Auto-aperfeiçoamento e emotividade & $-0,41$ \\
Auto-aperfeiçoamento e expectativas sociais & $-0,39$ \\
Auto-aperfeiçoamento e bom comportamento & $-0,45$ \\
Bom comportamento e autocontrole & 0,41 \\
\hline
\end{tabular}


Quanto mais as mães se preocupam com o desenvolvimento de autoconfiança e independência, menos elas valorizam que a criança aperfeiçoe sua capacidade para intimidade emocional com os outros. Da mesma forma, quanto maior o interesse para que o filho tenha um desenvolvimento pessoal, menor a preocupação para que ele atenda às expectativas sociais e tenha um comportamento apropriado ao se relacionar com os outros. Sendo a categoria autoaperfeiçoamento voltada para si e as outras três: emotividade, expectativas sociais e bom comportamento, relacionadas a um contexto e ao envolvimento de outras pessoas, é razoável perceber que quanto mais as mães se preocupam com que o filho desenvolva suas metas pessoais, menos elas valorizam o relacionamento interpessoal dele.

Além disso, observa-se que quanto maior o interesse no bom comportamento da criança, maior a preocupação para que ela controle seus impulsos negativos. Esse resultado pode ser explicado porque para se relacionar bem com os outros, ser obediente, não ser rebelde, entre outras características que fazem parte da categoria bom comportamento, muitas vezes é preciso que se tenham certos atributos que estão incluídos no autocontrole, tais como, ser paciente, não se estressar, não ser agressivo, entre outros.

Não terem sido encontradas correlações significativas das categorias e a idade e escolaridade dos pais e mães pode ser explicado pelo fato de não haver uma grande variação em relação à faixa etária e a escolaridade dos participantes. Nenhuma correlação significativa foi observada nos dados dos pais.

Admitindo que a dimensão individualista abranja as categorias de autoaperfeiçoamento e autocontrole e a dimensão sociocêntrica inclui as categorias expectativas sociais, emotividade e bom comportamento, a tabela 3 mostra a distribuição geral das respostas de pais e mães nessas duas dimensões.

Tabela 3: Percentual das respostas codificadas de pais e mães, segundo as categorias individualista e sociocêntrica.

\begin{tabular}{lcccc}
\hline Categorias & \multicolumn{2}{c}{ Mães } & \multicolumn{2}{c}{ P ais } \\
& Total & $\%$ & Total & $\%$ \\
\hline Individualista & 91 & 45,05 & 80 & 43,48 \\
Sociocêntrica & 111 & 54,95 & 104 & 56,52 \\
Total & 202 & 100 & 184 & 100 \\
\hline
\end{tabular}

Os participantes demonstraram ter uma tendência predominantemente sociocêntrica, valorizando mais a interdependência e a coletividade, assim como as mães agricultoras dos Camarões e as aldeãs da Índia, estudadas por Keller et al. ${ }^{10}$ Contudo, a diferença entre os percentuais das categorias sociocêntrica e individualista não foi muito grande, podendo indicar que o modelo cultural que visa o pertencimento grupal e o relacionamento com as pessoas não seja tão forte assim nesse grupo de participantes. É possível que eles tenham uma orientação autônomo-relacional onde se valoriza que os filhos se relacionem com outras pessoas e vivam harmonicamente em grupo, mas sem deixar de ser autônomos e independentes, conforme foi demonstrado pelas mães costarriquenhas, mexicanas, indianas e chinesas no estudo de Keller et al. ${ }^{10}$ Isso corrobora os resultados do estudo de Seidl-de- 
Moura et al. ${ }^{12}$ em sete capitais brasileiras que também encontrou uma tendência voltada para a autonomia e interdependência.

Comparando pais e mães, percebe-se que elas deram um pouco mais de respostas individualistas e eles mais respostas sociocêntricas. Isso pode demonstrar que talvez a orientação sociocêntrica seja um pouco mais forte nos homens do que nas mulheres dessa amostra. Como exemplo de mãe que apresentou uma tendência a valorizar metas individualistas pode-se citar a seguinte resposta:

“Todas, né? Ter bom caráter (ES), trabalhar bastante (AA), sempre dar valor naquilo que ele conseguir (AA), sempre com muita...fugiu até a palavra agora assim...não querendo nunca...nunca conseguir as coisas tendo que derrubar as pessoas (AC), conseguindo pelos seus próprios méritos da mesma forma que a gente sempre fez, assim, sendo pai e mãe. Ser educado (BC), é...seja qual profissão que ele queira seguir, fazer tudo com muita presteza (AA), seguir mesmo afinco (AA), pra ser um bom profissional, galgar tudo que tem de direito (AA), é...que mais? Acho que se ele se espelhar em pai e mãe ta ótimo porque tanto eu quanto meu marido, assim a gente é super complexo em tudo que faz, faz tudo querendo fazer sempre com a perfeição para não ter ninguém que cobre nada da gente. Eu acho que é isso. Eu acho que é isso. É, é isso.” (mãe-183).

Pode ser observado que no relato acima, foram identificadas oito características relacionadas às metas de socialização. Desse total, $75 \%$, ou seja, seis, estão relacionadas com o autoaperfeiçoamento (AA) ou autocontrole (AC), os quais fazem parte de uma orientação individualista, que mostra que ela deseja, acima de tudo, que ele se desenvolva pessoalmente.

O relato seguinte é de um pai com tendência sociocêntrica.

"Eu gostaria e trabalho pra isso, né, pra que ela seja uma, uma mulher sensível (EM). É...sensível as pessoas (EM), seja uma pessoa solidária (ES). É, no fundo, no fundo o que eu mais desejo é que ela seja realizada, né, na sua vida afetiva (EM), é, espiritual (ES), social (BC), profissional (AA). E portanto, para que ela seja realizada e portanto seja feliz eu acho que um dos caminhos pra que isso aconteça é que ela seja sensível as necessidades do outro (EM), que seja uma pessoa solidária (ES), que seja, que desenvolva na sua vida, é, categorias como a questão da justiça (ES), do respeito aos outros (BC), desbancando discriminações (AC), preconceitos (AC), que seja uma pessoa que tenha esse relacionamento social (BC)." (Pai-142).

Nesse caso, das quatorze características voltadas para as metas, onze, isto é, aproximadamente $80 \%$ delas são classificadas nas categorias emotividade (EM), expectativas sociais (ES) ou bom comportamento (BC), todas relacionadas à dimensão sociocêntrica, demonstrando uma valorização maior desse pai para que o seu filho se relacione e interaja com as pessoas.

Foram verificadas também as diferenças entre pais de meninos e meninas através do teste-t de Student, considerando-se estatisticamente significativos resultados para $\mathrm{p}<$ ou igual 0,05 . Não foi encontrada diferença significativa, mas os valores percentuais podem demonstrar algumas tendências, como mostra a tabela 4 .

Pais e mães de meninos e meninas valorizam as categorias de forma diferente. As mães de meninos parecem dar mais respostas de autoaperfeiçoamento que as mães de meninas, ao contrário das mães européias do estudo de Leyendecker ${ }^{11}$ que enfatizavam o autoaperfeiçoamento para as meninas. Em relação ao bom comportamento, parece ser uma categoria mais valorizada pelas mães nas meninas, o que pode ser compreendido pelo fato de tradicionalmente as regras de bom comportamento, como ter boas maneiras, um comportamento polido, causar boa impressão, serem mais rigorosas para as mulheres do que para os homens. Os pais parecem valorizar mais características relaci- 
Tabela 4: Percentual das repostas de pais e mães de meninas e meninos nas categorias de metas de socialização.

\begin{tabular}{ccccc}
\hline Categoria & $\begin{array}{c}\text { Mães de } \\
\text { meninos (\%) }\end{array}$ & $\begin{array}{c}\text { Participantes } \\
\text { Meninas (\%) }\end{array}$ & $\begin{array}{c}\text { Pais de } \\
\text { meninos (\%) }\end{array}$ & $\begin{array}{c}\text { Pais de } \\
\text { meninas (\%) }\end{array}$ \\
\hline Auto-aperfeiçoamento & 47 & 31 & 39 & 44 \\
Autocontrole & 3 & 9 & 0 & 4 \\
Emotividade & 11 & 13 & 4 & 12 \\
Expectativas sociais & 31 & 31 & 36 & 23 \\
Bom comportamento & 8 & 16 & 21 & 17 \\
\hline
\end{tabular}

onadas a expectativas sociais nos seus filhos do que em suas filhas e a emotividade foi mais relatada para as meninas.

Esses resultados podem demonstrar uma manutenção dos valores que eram tradicionalmente considerados importantes para homens, como ser trabalhador, estudar, ser inteligente, etc e para as mulheres, ser carinhosa, sensível, obediente, entre outras. Isso corrobora o que foi relatado por Biasoli-Alves ${ }^{6}$ sobre o fato de que, apesar das mulheres terem conquistado o direito a escolarização e trabalharem fora de casa, valores tradicionais como respeito, obediência, delicadeza no trato ainda permanecem, mesmo que de forma "encoberta".

Essa manutenção dos valores acontece porque os mesmos estão enraizados na cultura e para se modificarem totalmente levariam muito tempo. Além disso, seria preciso que não houvesse comunicação entre antigas e novas gerações, o que seria muito difícil em nossa sociedade, onde muitas vezes convivem avós, filhos e netos na mesma casa, fazendo com que o processo de transmissão de valores permaneça ${ }^{6}$.

Segunda pergunta: Estratégias para atingir as metas de socialização

$\mathrm{Na}$ análise da pergunta $\mathrm{n}^{\circ} 2$ "O que você acha que é necessário para que ele(a) possa desenvolver essas qualidades?” verificou-se que estratégias de ação eram mencionadas: centrada em si, no contexto ou na criança. Pais e mães acreditam que a participação deles é muito importante para que o seu filho possa desenvolver determinadas qualidades. Para eles, o modelo e os ensinamentos que oferecem seriam as principais formas de fazer seus filhos alcançarem certos atributos, como pode ser observado nas falas a seguir.

"...acho que tem muito a ver com o jeito que os pais criam...” (pai 001)

“...A família é fundamental...” (mãe 010)

"Eu acho que em primeiro lugar é... são os pais, a educação em casa...” (mãe 033)

Esse resultado também foi encontrado no estudo de Prado ${ }^{15}$ onde a principal estratégia utilizada por pais e mães era ser o modelo comportamental e referência de orientação.

Quanto às estratégias centradas no contexto, também são consideradas importantes, mas não tanto quanto as centradas em si. Abaixo seguem alguns exemplos desse tipo de estratégia.

“... uma boa escola...” (pai 067)

“Primeiro é um apoio do governo...” (pai 008)

“... que ele possa ter amigos...” (mãe

As estratégias que seriam voltadas para a criança não foram muito apontadas por ambos, podendo indicar que eles não estão muito inclinados a acreditar que as qualidades que a criança terá no futuro dependeriam da sua decisão ou do seu empenho. Entretanto, pode-se 
observar também que os pais parecem colocar mais a responsabilidade no próprio filho para o desenvolvimento dessas qualidades do que as mães. As frases a seguir são alguns exemplos de frases relatadas pelos pais.

“... eu acho que é uma coisa pra ela ir se virando sozinha...” (pai 001)

“... ela decide se faz o certo ou o errado...” (pai 019)

“... eu quero que ela trilhe o caminho..." (pai 055)

Em relação aos dois aspectos que fazem parte da categoria centrada em si, a tabela 5 mostra pais e mães enfatizando o aspecto cognitivo em detrimento do afetivo. Segue exemplos de relatos dos pais de ambos aspectos.
Afetivo: “...ter uma atenção, um bom carinho...” ( pai 006)

“... a gente possa dar afeto para ele...”

(mãe 140)

"É, que ele tem que ter muito carinho no crescimento dele...” (mãe 171)

Cognitivo: “...a gente procura educar, né, mostrando os caminhos corretos...” (pai 019)

“ Eu acho que é o exemplo que a gente dá pra ele, né, nas nossas ações, no nosso diaa-dia...” (mãe 126)

“... os filhos têm que se espelhar nos pais...” (pai 143)

Pais e mães também concordam que a principal forma dos seus filhos alcançarem as metas que eles desejam seria de sua respon-

Tabela 5: Percentual de respostas de mães e pais dos aspectos cognitivo e afetivo

\begin{tabular}{ccccc}
\hline Sujeitos & Mães & \multicolumn{2}{c}{ Pais } \\
Estratégias & Total de respostas & $\%$ & Total de respostas & $\%$ \\
\hline Cognitivo & 23 & 74,19 & 24 & 75 \\
Afetivo & 8 & 25,81 & 8 & 25 \\
Total & 31 & 100 & 32 & 100 \\
\hline
\end{tabular}

sabilidade e do(a) parceiro(a) e que o mais importante seria eles servirem como modelos, disciplinando, aconselhando e ensinando os filhos como gostariam que fossem. Nesse aspecto, o lado emocional não foi muito valorizado. Isso pode indicar que, para eles, quando se trata dos filhos desenvolverem qualidades, aconselhar e disciplinar é mais importante que a proteção, o carinho e o amor. Na pesquisa de Prado ${ }^{15}$ pais e mães também priorizaram o lado cognitivo, sendo que, comparando-se pais e mães, elas deram mais respostas afetivas que eles.

\section{CONSIDERAÇÕES FINAIS}

O presente estudo busca preencher parcialmente uma lacuna na literatura, trazendo algumas evidências de cognições parentais comparando respostas de pais e mães com relação ao que eles desejam para seus filhos no futuro. Nesse sentido, os resultados obtidos trazem contribuições relevantes à literatura da área. De qualquer forma, os autores reconhecem que o estudo apresenta algumas limitações como, por exemplo, o tamanho da amostra. As cognições parentais sobre metas de socialização foram estudadas através da resposta a duas perguntas abertas. Embora o procedimento de análise de conteúdo venha sendo utilizado em diversas pesquisas e trazendo resultados relevantes e consistentes, novos instrumentos poderão ser desenvolvidos e/ou adaptados para uso em estudos futuros, com grupos maiores de pais e mães, inclusive de outras regiões do Brasil. Com isso, os modelos culturais de parentagem de pais brasileiros serão melhor compreendidos, assim como aspectos importantes desse contexto de desenvolvimento, permitindo comparações com resultados em outras culturas. 


\section{REFERÊNCIAS}

1. Moinhos MV, Lordelo ER., Seidl-deMoura ML. Metas de socialização de mães baianas de diferentes contextos socioeconômicos. Revista Brasileira de Crescimento e Desenvolvimento Humano 2007; 17(1): 114-125.

2. Ribas RCJR, Seidl-de-Moura ML, Bornstein MH. Cognições maternas acerca da maternidade e do desenvolvimento humano: uma contribuição ao estudo da psicologia parental. Revista Brasileira de Crescimento e Desenvolvimento Humano 2007; 17(1): 104-113.

3. Harkness S, Super CM. Developmental niche: a theoretical framework for analyzing the household production of health. Social Science and Medicine 1994; 38(2): 219-226.

4. Lightfoot C, Valsiner J. Parental belief systems under the influence: social guidance of the construction of personal cultures. In: Siegel IS, Mcgillicudydelisi AV, Goodnow J. Parental belief systems: The psychological consequences for children . Hillsdale, NJ e Hove, UK: Lawrence Erlbaum; 1992. p.393-414.

5. Ribas RCJR. Cognição de mães brasileiras acerca da maternidade, da paternidade e do desenvolvimento humano: Uma contribuição ao estudo da psicologia parental. [projeto de tese] Rio de Janeiro (RJ): Programa de PósGraduação em Psicologia Social; 2002.

6. Biasoli-Alves ZMM. Continuidades e rupturas no papel da mulher brasileira no Século XX. Psicologia: Teoria e Pesquisa 2000;16(3):233-239.

7. Keller H, Borke J, Yovsi R. Cultural orientations and historical changes as predictors of parenting behaviour, International Journal of Behavior Development 2005; 29(3):229-237.

8. Kagitçibasi Ç. The autonomous-relational self: a new synthesis. European Psychologist 1996; 1(3):180-186.
9. Kagitçibasi Ç. Autonomy and relatedness in cultural context: Implications for self and family. Journal of Cross-Cultural Psychology 2005; 36: 403-422.

10. Keller H, Lamm B, Abels M, Yovsi R, Borke J, Jensen H, Papaligoura Z, Holub C, Lo W, Tomiyama J, Su Y, Wang Y, Chaudhary N. Cultural models, socialization goals and parenting ethnotheories, Journal of Cross-cultural Psychology 2006; 37(2):155-172.

11. Leyendecker B, Lamb ME, Harwood RL, Sholmerich A. Mothers' socialization goals and evaluating of desirable and undesirable everyday situations in two diverse cultural groups. International Journal of Behavioral Development 2002; 26(3): 248-258.

12. Seidl-de-moura ML, Lordelo E, Vieira ML, Piccinnini CA, Siqueira JEO, Magalhães C MC, Pontes FAR, Salomão NM, Rimoli A. Brazilian mothers' socialization goals: Intracultural differences in seven Brazilian cities. International Journal of Behavioral Development 2008; 32(6): 465-472.

13. Harwood RL, Schoelmerich A, Schulze PA, Gozalez Z. Cultural differences in maternal beliefs and behaviors: a study of middle-class Anglo and Puerto Rican mother-infant pairs in four everyday situations. Child Development 1999; 70(4): 1005-1016..

14. Cabrera N, Tamis-lemonda CS, Bradley RH, Hofferth S, Lamb ME. Fatherhood in the Twenty-First Century. Child Development; 2000 71(1):127-136.

15. Prado AB. Semelhanças e diferenças entre homens e mulheres na compreensão do comportamento paterno. [dissertação]. Florianópolis (SC): Programa de Pós-Graduação em Psicologia; 2005.

Recebido em: 28 de junho de 2008. Modificado em: 10 de março de 2009. Aceito em: 25 de maio de 2009. 